\title{
Effect of ephedrine combined with bupivacaine on maternal hemodynamic and spinal nerve block in cesarean delivery
}

\author{
MINGYUE GE, SHENG WANG, ZHIGANG DAI, YAN LI, LIPING XIE, XUEJAO LIU and JIANGWEN YIN \\ Department of Anesthesiology, First Affiliated Hospital, School of Medicine, \\ Shihezi University, Shihezi, Xinjiang 832002, P.R. China
}

Received August 12, 2016; Accepted January 12, 2017

DOI: $10.3892 /$ br.2017.846

\begin{abstract}
The aim of the study was to investigate the effects of ephedrine intrathecal injection on maternal thermodynamics and spinal nerve block in cesarean section. A total of 107 patients undergoing elective cesarean section under combined spinal epidural anesthesia were randomly divided into two groups: group E: Bupivacaine $(6 \mathrm{mg})$ combined with ephedrine $(15 \mathrm{mg})$ and group C: Bupivacaine $(6 \mathrm{mg})$. Systolic blood pressure (SBP), diastolic blood pressure (DBP), heart rate (HR), the incidence of hypotension, hypertension, tachycardia, nausea and vomiting were all recorded. The umbilical vein blood gases and noradrenaline, as well as maternal peripheral venous blood were analyzed. The time of high-quality spinal block was also recorded. Postoperatively, 1 day, 2 days bedside follow-up and 7, 21, 35 days telephone follow-up were carried out to determine any neurological deficit maternal performance. SBP and DBP decreased in group $\mathrm{C}$ but not in group $\mathrm{E}$ at $3 \mathrm{~min}$ after spinal anesthesia and $1 \mathrm{~min}$ after delivery $(\mathrm{P}<0.05)$. From $3 \mathrm{~min}$ post-anesthesia to the end of surgery, the HR levels in the $\mathrm{C}$ group were significantly higher than those of the $\mathrm{E}$ group $(\mathrm{P}<0.05)$. The incidence of hypotension, tachycardia, nausea and vomiting and neonate acidosis was low in group $\mathrm{E}$ compared with group $\mathrm{C}(\mathrm{P}<0.05)$. The time of high-quality spinal block in group $\mathrm{E}$ was longer than that of group $\mathrm{C}(\mathrm{P}<0.05)$. After spinal anesthesia, the concentration of noradrenaline from maternal peripheral venous blood was low in group $\mathrm{C}$ but high in group E compared with before spinal anesthesia $(\mathrm{P}<0.05)$. Ephedrine combined with low-dose bupivacaine intrathecal injection effectively maintained maternal hemodynamics and prolonged the time of sensory spinal block.
\end{abstract}

Correspondence to: Dr Sheng Wang, Department of Anesthesiology, First Affiliated Hospital, School of Medicine, Shihezi University, 280 N 4th Road, Shihezi, Xinjiang 832002, P.R. China

E-mail: iamsheng2006@163.com; shz39931705@163.com

Key words: ephedrine, low-dose bupivacaine spinal anesthesia, cesarean section

\section{Introduction}

Spinal anesthesia provides fast, profound, and high-quality block characteristics, and remains the preferred choice for cesarean deliveries worldwide $(1,2)$. Hypotension is the most common serious adverse effect of spinal anesthesia for cesarean deliveries, and the incidence of hypotension after spinal anesthesia is $>80 \%$ (3). Hypotension is the physiological consequence of spinal anesthesia and can have a potentially deleterious maternal and fetal impact (4). Therefore, prevention and treatment of the negative effects, with special medical agents for the optimal sustaining of the mother's blood pressure and fetal's circulation are an important issue $(5,6)$. Although studies have compared different measures to elevate the hypotension induced by regional anesthesia, vasopressors are nevertheless required to treat any significant hypotension (7). Previous findings revealed the development of hypotension after spinal block in subjects undergoing cesarean section was not prevented despite low-dose bupivacaine; however, the severity of maternal hypotension, the number of ephedrine treatments, and the total dose of ephedrine were decreased (8). Previous results indicated that phenylephrine and ephedrine are acceptable choices to combat maternal hypotension related to spinal anesthesia in elective cesarean section, but the incidences of bradycardia were significantly higher in the phenylephrine group (9).

Ephedrine is the most commonly used drug among the vasopressors (1). Since ephedrine systemic absorption and peak effect are difficult to predict, the prophylactic administration of ephedrine by the intramuscular route is very controversial $(10,11)$. The intravenous route may be more effective and controllable, but ephedrine has been involved in lower umbilical $\mathrm{pH}$ levels, especially when used in dosages high enough to stem nausea and vomiting related to hypotension $(9,12,13)$. We hypothesized that ephedrine combined with low-dose bupivacaine intrathecal injection would be conductive to maintaining stability in maternal hemodynamic. Even at the large amount of $30 \mathrm{mg}$, the intrathecal injection of ephedrine is considered safe (14).

The aim of the present study was to investigate the effectiveness and the side effects of intravenous phenylephrine and ephedrine in combating maternal hypotension resulting from spinal anesthesia in patients undergoing elective cesarean section. 


\section{Materials and methods}

The present study was approved by the Ethics Committee of the First Affiliated Hospital of Shihezi University School of Medicine in China, and is registered in the Chinese Clinical Trial Register (no. ChiCTR-IPR-14005477). The present study was registered prior to enrolling subjects in the study. All the patients provided written informed consent prior to inclusion.

This prospective, double-blind, randomized, controlled and single-center study was designed in 2013 and performed at the First Affiliated Hospital of Shihezi University School of Medicine, a teaching hospital of Capital Medical University, China. Included in the present study were 107 patients who underwent elective cesarean section between June, 2014 and April, 2015. The inclusion criteria were: Healthy and nulliparous women with a signal, vertex presentation fetus at term (38-42 weeks), ASA physical status I or II, and undergoing elective cesarean delivery under combined spinal-epidural anesthesia. The exclusion criteria included: Age $<18$ or $>40$ years of age, height $<150$ or $>180 \mathrm{~cm}$, weight $<50$ or $>100 \mathrm{~kg}$, the presence of systemic disease (e.g., preeclampsia, hypertension, diabetes mellitus), contraindications to an epidural technique, an allergy or idiosyncratic reaction to local anesthetic or opioid medications, an increased risk of cesarean delivery (e.g., trial of labor after cesarean delivery, history of uterine rupture), evidence of anticipated fetal anomalies, clinical signs or symptoms of infection, and signs of labor onset.

The patients underwent preoperative fasting for $8 \mathrm{~h}$ and water deprivation for $>4 \mathrm{~h}$. The patients were taken to the operating room, and administered $8 \mathrm{ml} / \mathrm{kg}$ of lactated Ringer's injection, within $20 \mathrm{~min}$, via a 20 -gauge cannula placed in a forearm vein. The infusion speed was then adjusted to $6 \mathrm{ml} / \mathrm{kg} / \mathrm{h}$. Each patient was randomly assigned to one of the two double-blind study groups. The patients were in a supine position for $\geq 30$ min before the collection of their blood. Patients were positioned in the right lateral position with flexion of thigh and legs, hip and knees and flexion at the head. Using aseptic precautions, lumbar puncture was performed at L3-4 using midline approach with 23G sterile Quinke's needle. After visualization of clear and free flow of cerebrospinal fluid, Group E received $2 \mathrm{ml}$ of $0.25 \%$ bupivacaine, containing $15 \mathrm{mg}$ ephedrine and Group $\mathrm{C}$ was given $2 \mathrm{ml}$ of $0.25 \%$ bupivacaine. After anesthesia, patients were assisted into a supine position and care was taken regarding the block plane prior to surgery, once again for maternal blood collection.

The baseline SAP and heart rate (HR), lowest and highest SBP and HR, nausea, vomiting, dizziness, and chest symptoms were recorded every minute. The upper sensory level of anesthesia was measured by assessing loss of pinprick discrimination at $10 \mathrm{~min}$. The blocks extended to T6 or above, prior to the initiation of surgery. Once hypotension occurred, defined as decrease in systolic blood pressure of $<90 \mathrm{~mm}$ $\mathrm{Hg}$ and/or 30\% less than the basal Systolic blood pressure, patients were given ephedrine intravenously. The first rescue ephedrine time, total doses of rescue ephedrine, and total dose of used ephedrine, duration of surgery, and time of neonate extraction were all recorded as minutes after the beginning of surgery. Incidences of bradycardia ( $\mathrm{HR}<60 \mathrm{bpm})$ were treated with $0.5 \mathrm{mg}$ atropine i.v.; and any tachycardia (HR $>30 \%$

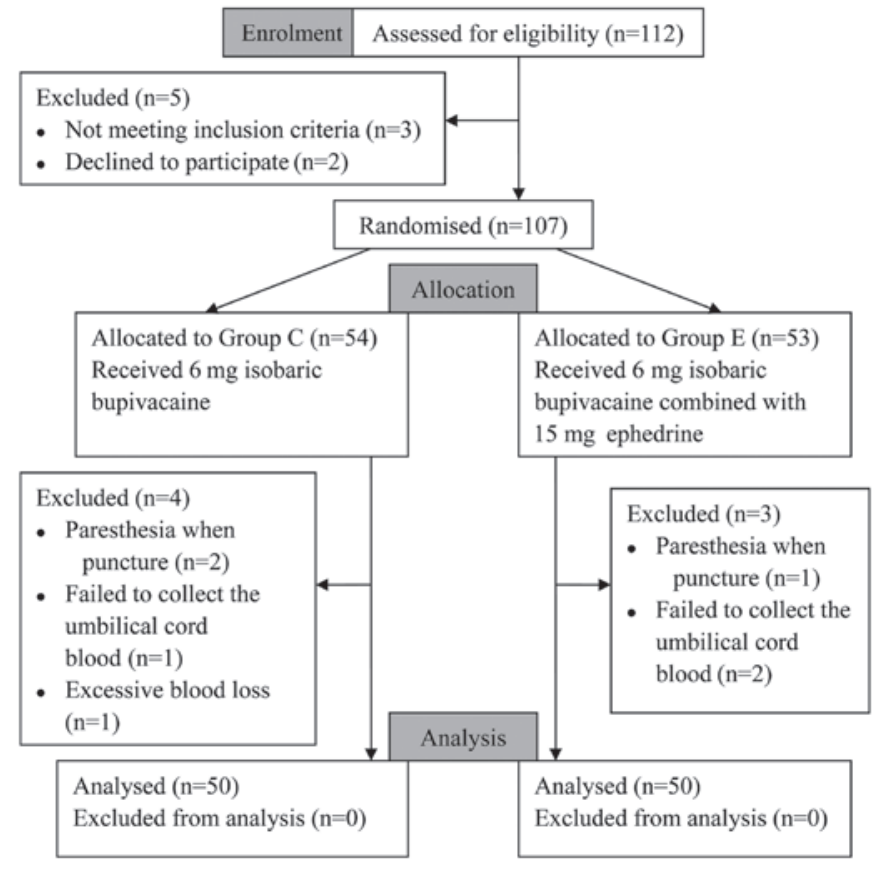

Figure 1. Flow diagram of patient distribution.

above the basal HR) was noted. After delivery, Apgar score was assessed at 1 and $5 \mathrm{~min}$ by the attending pediatrician. Arterial blood samples were taken from the umbilical cord for blood-gas analysis within $2 \mathrm{~min}$. After baby extraction, all the patients received 20 units oxytocin by infusion through a separate line. Maternal plasma noradrenaline was measured by high-performance liquid chromatography.

Statistical analysis. The primary outcome was the incidence of hypotension. The sample size was calculated according to our preliminary data. A minimum of 50 patients in each group provided $90 \%$ statistical power to detect a $30 \%$ difference (from 50 to $20 \%$ ) in the incidence of hypotension, at a two-sided $\mathrm{P}<0.05$. Considering a presumed dropout rate of $20 \%, 70$ patients were initially enrolled in each of the two groups.

SPSS 17.0 software (SPSS, Inc., Chicago, IL, USA) was used for statistical analyses. Data were analyzed using the Shapiro-Wilk test to determine the distribution. If normally distributed, the data were presented as mean \pm standard deviation and two independent groups were compared using the Student's t-test. Data not distributed normally were presented as median (min-max), and were analyzed using a Mann-Whitney U test. Categorical variables were analyzed by using a Chi-square test, or Fisher's exact test if the number of subjects in any contingency table cell was expected to be $<5$. $\mathrm{P}<0.05$ was considered to indicate a statistically significant difference.

\section{Results}

Patient data. The present study was conducted between June, 2014 and April, 2015. Initially, 112 patients were assessed for study eligibility. Five subjects were excluded from the study, of whom 3 did not meet the inclusion criteria 
Table I. Demographic data in the two groups (data expressed as mean \pm standard deviation).

\begin{tabular}{lccc}
\hline Variables & $\begin{array}{c}\text { Group C } \\
(\mathrm{n}=50)\end{array}$ & $\begin{array}{c}\text { Group E } \\
(\mathrm{n}=50)\end{array}$ & P-value \\
\hline Age (years) & $26.86 \pm 5.23$ & $28.12 \pm 4.87$ & 0.22 \\
Weight (kg) & $73.66 \pm 10.61$ & $77.62 \pm 12.11$ & 0.09 \\
Height (cm) & $161.20 \pm 5.26$ & $163.00 \pm 4.60$ & 0.07 \\
Weeks of & $37.20 \pm 1.03$ & $37.64 \pm 1.33$ & 0.07 \\
gestation (week) & & & \\
Time of baby & $13.16 \pm 3.72$ & $14.86 \pm 5.00$ & 0.06 \\
extraction (min) & & & \\
$\begin{array}{l}\text { Duration of } \\
\text { surgery (min) }\end{array}$ & $82.10 \pm 12.41$ & $78.46 \pm 10.07$ & 0.11 \\
\hline
\end{tabular}
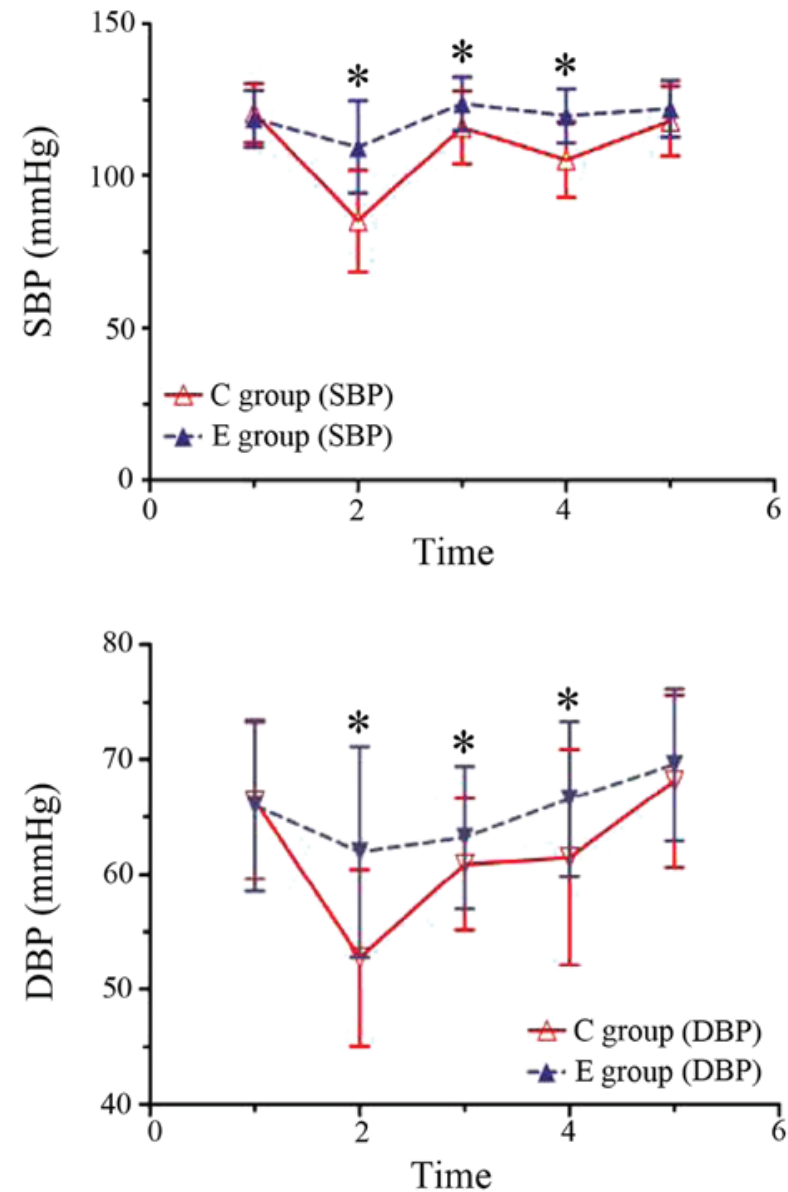

Figure 2. Systolic and diastolic arterial pressure of the ephedrine and control groups.

and 2 declined to participate, and the remaining 107 subjects were randomized. Group C included 54 subjects and group E 53 subjects. Subsequently, 4 subjects were excluded from group $\mathrm{C}$ and 3 from group E. Finally, there were 50 patients analyzed in each group (Fig. 1).

The demographic characteristics of the two groups were similar. There were no statistical differences between the groups with respect to age, weight, height, gestational weeks, delivery time and operative time (Table I). Sensory blockade extended to T6 and above within $15 \mathrm{~min}$ in all the patients. All the patients had adequate surgical anesthesia.

Blood pressure and HR. There was no significant difference in the SBP and HR vaues at baseline between the study groups (P>0.05). Post-anesthesia $3 \mathrm{~min}$ and $1 \mathrm{~min}$ after the delivery of the fetus, the mean BPs in group $\mathrm{C}$ were significantly lower than those of group $\mathrm{E}(\mathrm{P}<0.05)$, and significant decreases of the mean $\mathrm{BP}$ were observed in group $\mathrm{C}$ compared to the baseline $(\mathrm{P}<0.05)$. However, no difference of the mean BP in group $\mathrm{E}$ was observed compared to the the baseline ( $\mathrm{P}>0.05)$ (Fig. 2). From post-anesthesia $3 \mathrm{~min}$ to the end of the surgery, the HR levels in group $\mathrm{C}$ were significantly higher than those of group $\mathrm{E}(\mathrm{P}<0.05)$. Before the delivery of the fetus, significant increases of the HR in group $\mathrm{C}$ were observed as compared with the baseline $(\mathrm{P}<0.05)$, but no difference of the $\mathrm{HR}$ in group $\mathrm{E}$ was observed as compared with the baseline $(\mathrm{P}>0.05)$. Following delivery of the fetus, significant decreases of the $\mathrm{HR}$ in groups $\mathrm{C}$ and $\mathrm{E}$ were observed as compared with the baseline $(\mathrm{P}<0.05)$ (Fig. 3). The total doses of ephedrine mean were $54.47,46.53, \mathrm{P}=0.139$ in the two groups respectively, and there were no obvious differences.

Complications. The incidences of hypotension, hypertension, tachycardia, nausea or vomiting, and neonatal acidosis are summarized in Table II. There was a significant decrease in the incidence of hypotension in group $\mathrm{E}$ compared with group $\mathrm{C}$ [6 (12\%) vs. $40(80 \%)](\mathrm{P}<0.01)$. There were significantly lower incidences of tachycardia in group $\mathrm{E}$ compared with group $\mathrm{C}$ [6 (12\%) vs. $22(44 \%)](\mathrm{P}<0.01)$. There were significantly lower incidences of nausea and vomiting in group $\mathrm{E}$ compared with group C [5 (10\%) vs. $31(62 \%)](\mathrm{P}<0.01)$. There were significant lower incidences of neonatal acidosis in the $\mathrm{E}$ group compared with the $\mathrm{C}$ group [3 (6\%) vs. $17(34 \%)](\mathrm{P}<0.01)$. There was no difference in the ratio of hypertension between the study groups $(\mathrm{P}>0.05)$.

Sensory block and plasma norepinephrine levels. The effects of ephedrine intrathecal injection on sensory blockade and maternal plasma noradrenaline are shown in Table III. There were no differences in the extent of sensory blockade or time-intervals. However, the sensory blockade duration in the group $\mathrm{E}$ was significantly longer than that of group $\mathrm{C}$ $(\mathrm{P}<0.01)$. Before and after anesthesia, the maternal plasma noradrenaline content was altered, and significant decreases of the maternal plasma noradrenaline content in group $\mathrm{C}$ were observed as compared with baseline $(\mathrm{P}<0.05)$. However, significant increases of the maternal plasma noradrenaline content in group $\mathrm{E}$ were observed as compared with baseline $(\mathrm{P}<0.05)$. There was no difference of the maternal plasma noradrenaline content baseline in groups $\mathrm{E}$ and $\mathrm{C}(\mathrm{P}>0.05)$. After anesthesia, the maternal plasma noradrenaline content in group $\mathrm{C}$ was significantly lower than that of group $\mathrm{E}(\mathrm{P}<0.01)$.

Postoperative follow-up results showed that the two groups had no neurological deficits performance $(\mathrm{P}>0.05)$.

\section{Discussion}

The current study is the first report, to the best of our knowledge, to investigate the effects of ephedrine combined with 
Table II. Intraoperative complications in both groups.

\begin{tabular}{lccr}
\hline Variables & $\begin{array}{c}\text { Group C } \\
(\mathrm{n}=50, \%)\end{array}$ & $\begin{array}{c}\text { Group E } \\
(\mathrm{n}=50, \%)\end{array}$ & P-value \\
\hline Hypotension & $40(80)$ & $6(12)$ & $<0.01$ \\
Hypertension & $4(8)$ & $7(14)$ & 0.34 \\
Tachycardia & $22(44)$ & $6(12)$ & $<0.01$ \\
Bradycardia & $3(6)$ & $5(10)$ & 0.46 \\
Nausea or vomiting & $31(62)$ & $5(10)$ & $<0.01$ \\
Neonatal acidosis & $17(34)$ & $3(6)$ & $<0.01$ \\
\hline
\end{tabular}

Table III. Time of sensory block and plasma norepinephrine levels in the two groups (data expressed as mean \pm standard deviation).

\begin{tabular}{lccc}
\hline Variables & $\begin{array}{c}\text { Group C } \\
(\mathrm{n}=50)\end{array}$ & $\begin{array}{c}\text { Group E } \\
(\mathrm{n}=50)\end{array}$ & P-value \\
\hline $\begin{array}{l}\text { Time of sensory } \\
\text { block to T6, min }\end{array}$ & $7.65 \pm 1.27$ & $8.06 \pm 1.76$ & 0.18 \\
$\begin{array}{l}\text { Duration of sensory } \\
\text { block to T6, min }\end{array}$ & $32.24 \pm 5.37$ & $50.30 \pm 4.90$ & $<0.01$ \\
$\begin{array}{l}\text { Basal level of } \\
\text { maternal plasma }\end{array}$ & $376.10 \pm 24.78$ & $367.07 \pm 25.32$ & 0.08 \\
$\begin{array}{l}\text { norepinephrine, ng/1 } \\
\begin{array}{l}\text { Plasma norepinephrine } \\
\text { levels after anesthesia } \\
8 \text { min, ng/l }\end{array}\end{array}$ & & & \\
\hline
\end{tabular}

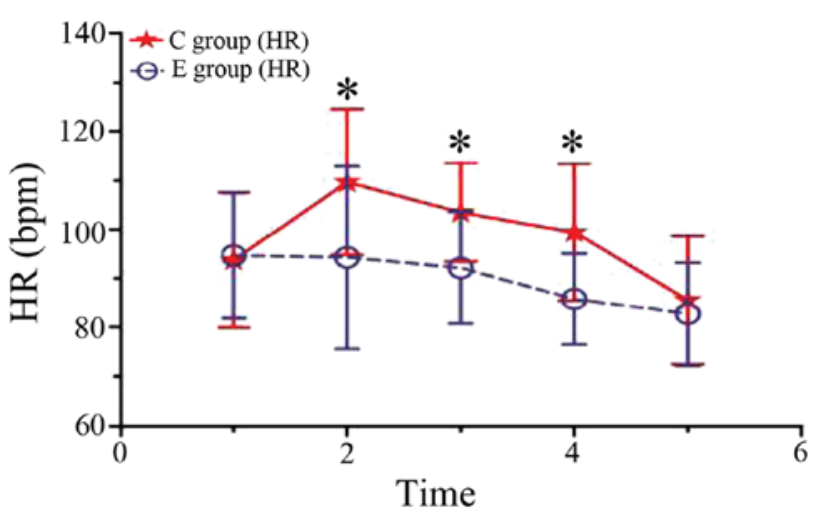

Figure 3. Heart rate of the maternal of two groups.

low-dose bupivacaine on maternal hemodynamics and spinal nerve block in cesarean deliveries. Our findings demonstrated that prophylactic subarachnoid injection of ephedrine during spinal anesthesia for cesarean section can prevent hypotension without significant maternal tachycardia or hypertension, decrease the ratio of nausea and vomiting, improve the neonatal condition, and decrease the ratio of neonatal acidosis. In addition, ephedrine combined with low-dose bupivacaine subarachnoid injection prolonged the sensory blockade duration of spinal anesthesia by bupivacaine.
The incidence of hypotension during spinal anesthesia for cesarean section is reported to be $\leq 80 \%$, despite fluid preload, lateral uterine displacement, low-dose bupivacaine spinal anesthesia and use of vasopressor agents (15). In the anesthesia practice, prevention and management of hypotension related to spinal anesthesia remains a difficult problem and there has been no consensus on its optimal management.

Ephedrine, an indirectly acting sympathomimetic amine, is probably the vasopressor of choice in obstetric anesthesia. Although ephedrine has mixed $\alpha$-and $\beta$-adrenoreceptor activity, it maintains arterial pressure mainly by increases in cardiac output and heart rate as a result of its predominant activity on $\beta 1$-adrenoreceptors (16). However, a meta-analysis of four randomized clinical trials by Lee et al showed that ephedrine could not be used for prophylaxis against hypotension, as it cannot prevent hypotension in low doses, and in high doses, it may cause hypertension (17). In addition, studies have shown that a decrease in neonatal $\mathrm{PH}$ and $\mathrm{BE}$ is correlated with high-dose ephedrine used in obstetrical anesthesia $(12,18)$. Previous studies have found that intravenous ephedrine can pass through the placenta into the fetus, thereby increasing fetal metabolism, causing poor umbilical artery and vein blood $\mathrm{PCO}_{2}$ increase, resulting in neonate academia (19). Our results have shown that, while both groups used the ephedrine dosage, the incidence of neonatal acidosis in the intrathecal group was significantly lower than that of the intravenous group, which indicated that maternal subarachnoid injected ephedrine does not have obvious adverse effects on the fetus. This shows indirectly that ephedrine in subarachnoid injection may be little or not absorbed into the blood. Spinal anesthesia is prone to hypotension, and it occurs early in sensory and motor block, due to spinal nerve roots within the unmyelinated sympathetic nerve fibers and sensory fibers, showing local anesthetics are more sensitive. Subarachnoid injection in the present study on stabilizing hemodynamic effect of ephedrine may be directly blocked by the local anesthetics on sympathetic nerve fibers in the spinal nerve root block.

Clinical trials found that dexmedetomidine has a dose-dependent effect on the onset and regression of sensory and motor block when used as an adjuvant to bupivacaine in spinal anesthesia (20). As a non-specific adrenergic receptor agonist, ephedrine can be to combined directly with $\alpha-2$ receptors in the dorsal horn of the spinal cord, inhibiting class $\mathrm{C}$ and class $\mathrm{A}$ afferent nerve fibers of pain impulses, thereby inhibiting prominent former neurotransmitter release and dorsal horn neuron hyperpolarization (21). By blocking the $\mathrm{Na}^{+}$internal flow and the generation and conduction of nerve impulses, local anesthetic acts as a nerve block. The results of the present study show that the sensory blockade duration in group E were significantly longer than those of group C, suggesting that ephedrine combined with bupivacaine subarachnoid injection prolongs spinal anesthesia sensory block duration. This phenomenon may show the synergistic effects of subarachnoid injection of the two drugs on nerve fibers. This is consistent with the animal experimental study of Djalali (22). Kroin et al reported that clonidine prolonging the effect of peripheral nerve block is achieved by adjusting the hyperpolarization-activated cation current, and it is independent of $\alpha$ receptors (23). In the present study, while the mechanism of ephedrine prolonging 
the duration of sensory block was the same, further investigation is needed.

In conclusion, the findings of the present study, show that prophylactic use of phenylephrine infusion can prevent mother's hypotension induced by spinal anesthesia in cesarean delivery, without any significant adverse effect on the mother or her fetus, improves neonatal condition and prolongs the sensory blockade duration of spinal anesthesia by bupivacaine.

\section{Acknowledgements}

The present study was partially supported by the First Affiliated Hospital of Shihezi University School of Medicine Research Project (no. YL-2013-R009).

\section{References}

1. Kol IO, Kaygusuz K, Gursoy S, Cetin A, Kahramanoglu Z, Ozkan F and Mimaroglu C: The effects of intravenous ephedrine during spinal anesthesia for cesarean delivery: A randomized controlled trial. J Korean Med Sci 24: 883-888, 2009.

2. Moslemi F and Rasooli S: Comparison of prophylactic infusion of phenylephrine with ephedrine for prevention of hypotension in elective cesarean section under spinal anesthesia: A randomized clinical trial. Iran J Med Sci 40: 19-26, 2015.

3. Tamilselvan P, Fernando R, Bray J, Sodhi M and Columb M: The effects of crystalloid and colloid preload on cardiac output in the parturient undergoing planned cesarean delivery under spinal anesthesia: A randomized trial. Anesth Analg 109: 1916-1921, 2009.

4. De-Giorgio F, Grassi VM, Vetrugno G, d'Aloja E, Pascali VL and Arena V: Supine hypotensive syndrome as the probable cause of both maternal and fetal death. J Forensic Sci 57: 1646-1649, 2012.

5. Miller R, Eriksson L, Fleisher L, Wiener-Kronish J and Young W (eds): Anaesthesia for Orthopaedic Surgery. In: Miller's Anesthesia. Vol 2. 7th edition. Churchill Livingstone Publishers, Philadelphia (PA), p2252, 2010.

6. Simin A, Zahra F, Pouya HM and Reza T: Comparison of the effect of ephedrine and phenylephrine in treatment of hypotension after spinal anesthesia during cesarean section. Open J Obstet Gynecol 2: 192-196, 2012.

7. Loubert C: Fluid and vasopressor management for Cesarean delivery under spinal anesthesia: continuing professional development. Can J Anaesth 59: 604-619, 2012.

8. Turhanoglu S, Kaya S and Erdogan H: Is there an advantage in using low-dose intrathecal bupivacaine for cesarean section? J Anesth 23: 353-357, 2009.

9. Gunda CP, Malinowski J, Tegginmath A, Suryanarayana VG and Chandra SB: Vasopressor choice for hypotension in elective Cesarean section: Ephedrine or phenylephrine? Arch Med Sci 6 : $257-263,2010$
10. Bhar D, Bharati S, Halder PS, Mondal S, Sarkar M and Jana S: Efficacy of prophylactic intramuscular ephedrine in prevention of hypotension during caesarean section under spinal anaesthesia: A comparative study. J Indian Med Assoc 109: 300-303, 307, 2011.

11. Egger C, McCrackin M-A, Hofmeister E, Touzot-Jourde G and Rohrbach B: Efficacy of preanesthetic intramuscular administration of ephedrine for prevention of anesthesia-induced hypotension in cats and dogs. Can Vet J 50: 179-184, 2009.

12. Veeser M,Hofmann T, Roth R, Klöhr S, Rossaint R and Heesen M: Vasopressors for the management of hypotension after spinal anesthesia for elective caesarean section. Systematic review and cumulative meta-analysis. Acta Anaesthesiol Scand 56: 810-816, 2012.

13. Lin FQ, Qiu MT, Ding XX, Fu SK and Li Q: Ephedrine versus phenylephrine for the management of hypotension during spinal anesthesia for cesarean section: An updated meta-analysis. CNS Neurosci Ther 18: 591-597, 2012.

14. Guo Q, Yao S, Wang G, et al: Clinical anesthesiology. Vol 4. 3rd edition. People's Medical Publishing Press, Beijing: pp.127-128, 2011.

15. Rout CC and Rocke DA: Prevention of hypotension following spinal anesthesia for cesarean section. Int Anesthesiol Clin 32: 117-135, 1994.

16. Critchley LA, Stuart JC, Conway F and Short TG: Hypotension during subarachnoid anaesthesia: Haemodynamic effects of ephedrine. Br J Anaesth 74: 373-378, 1995.

17. Lee A, Ngan Kee WD and Gin T: A dose-response meta-analysis of prophylactic intravenous ephedrine for the prevention of hypotension during spinal anesthesia for elective cesarean delivery. Anesth Analg 98: 483-490, 2004.

18. Aragão FF, Aragão PW, Martins CA, Salgado Filho N and Barroqueiro Ede S: Comparison of metaraminol, phenylephrine and ephedrine in prophylaxis and treatment of hypotension in cesarean section under spinal anesthesia. Rev Bras Anestesiol 64: 299-306, 2014 (In Portuguese).

19. Cooper DW, Carpenter M, Mowbray P, Desira WR, Ryall DM and Kokri MS: Fetal and maternal effects of phenylephrine and ephedrine during spinal anesthesia for cesarean delivery Anesthesiology 97: 1582-1590, 2002.

20. Al-Mustafa MM, Abu-Halaweh SA, Aloweidi AS, Murshidi MM, Ammari BA, Awwad ZM, Al-Edwan GM and Ramsay MA: Effect of dexmedetomidine added to spinal bupivacaine for urological procedures. Saudi Med J 30: 365-370, 2009.

21. Kawasaki Y, Kumamoto E, Furue H and Yoshimura M: Alpha 2 adrenoceptor mediated presynaptic inhibition of primary afferent glutamatergic transmission in rat substantia gelatinosa neurons. Anesthesiology 98: 682-689, 2003.

22. Djalali AG, Wang JC-F, Perez-Valdivieso JR, Danninger T, Fritsch G, Zurakowski D and Gerner P: Ephedrine shows synergistic motor blockade when combined with bupivacaine or lidocaine for spinal anesthesia in a rat model. Anesth Analg 116: 944-948, 2013 .

23. Kroin JS, Buvanendran A, Beck DR, Topic JE, Watts DE and Tuman KJ: Clonidine prolongation of lidocaine analgesia after sciatic nerve block in rats Is mediated via the hyperpolarization-activated cation current, not by alpha-adrenoreceptors. Anesthesiology 101: 488-494, 2004. 